\title{
TAREFA MATEMÁTICA INVESTIGATIVA NO ENSINO MÉDIO: UMA ANÁLISE DE RESOLUÇÕES DE TRÊS ESTUDANTES INVESTIGANDO O TRIÂNGULO DE PASCAL
}

\section{MATHEMATICS INQUIRY TASK IN THE UPPER GRADES OF HIGH SCHOOL: AN ANALYSIS OF THREE STUDENTS' RESOLUTIONS INVESTIGATING THE PASCAL TRIANGLE}

\section{Messenas Miranda Rocha}

Instituto Federal do Espírito Santo

E-mail: messenas.rocha@ifes.edu.br

\section{Vânia Maria Pereira dos Santos-Wagner \\ Universidade Federal do Espírito Santo \\ E-mail: profvaniasantoswagner@gmail.com}

\section{Resumo}

Este artigo focaliza nas resoluções de três alunos de Ensino Médio em uma tarefa investigativa com o Triângulo de Pascal. Na pesquisa, investigou-se o potencial de tarefas de resolução de problemas e tarefas investigativas em aulas de Matemática e a importância dessas tarefas no processo educativo. Os alunos foram instigados a registrar observações, estabelecer relações, conjecturar e argumentar sobre suas conclusões durante a realização de tarefas investigativas. Percebemos que alguns alunos mudaram crenças, concepções e atitudes sobre a Matemática, seu ensino e aprendizagem. Acreditamos que tarefas investigativas, quando realizadas pelos alunos em situações desafiantes e de complexidade adequada ao nível de desenvolvimento matemático deles, podem colocá-los no papel de matemáticos.

Palavras-chave: tarefa investigativa. triângulo de Pascal. Ensino Médio. Matemática.

\begin{abstract}
This article focuses on three high school students' resolutions in an investigative task with Pascal's Triangle. In this research it was investigated the potential of problem-solving tasks and investigative tasks in mathematics lessons and the importance of these tasks in the educational process. The students were encouraged to recording observations, establishing relationships, conjecturing and arguing about their findings while conducting investigative tasks. We realize that some students have changed beliefs, conceptions and attitudes about mathematics teaching and learning. We believe that investigative tasks, when performed by students in challenging situations and with adequate complexity to their mathematical development level, can put them in the role of mathematicians.
\end{abstract}

Palavras-chave: investigative task. Pascal's triangle. High School. Mathematics. 


\section{INTRODUÇÃO}

Durante o desenvolvimento de uma atividade de matemática, temos verificado, com a prática, como é difícil auxiliar de maneira adequada os alunos, sem ajudá-los demais e sem deixá-los sozinhos e sem ideias de como agir, para que resolvam a tarefa que lhes propomos em aulas. Segundo a teoria de Vygotsky, essa possibilidade de alteração do desempenho de uma pessoa pela interferência de outra é fundamental para a aprendizagem, pois Vygotsky percebe aprendizagem como um processo profundamente social, enfatiza diálogo e os vários papéis que a linguagem desempenha em instrução e em mediar crescimento cognitivo (JOHN-STEINER; SOUBERMAN, 1978, p. 131). Oliveira (1993), também fundamentada na teoria de Vygotsky, comenta que o desenvolvimento individual se dá num ambiente social determinado e a relação com o outro, nas diversas esferas e níveis da atividade humana, é essencial para o processo de construção do ser psicológico individual (p. 60). É preciso conhecer o nível em que o aluno se encontra e valorizar as interações sociais e diálogos em aulas, mas, quando entramos em sala de aula, parece que alguns de nós, professores, desconsideramos esses fatos.

Algumas vezes nós vamos logo resolvendo os exercícios no quadro, sem incentivarmos a análise do problema pelos alunos para percebermos o que eles compreendem. Ou seja, acabamos por nem procurar identificar onde cada aluno se encontra na atividade, quer seja na fase de leitura, de compreensão e/ou de análise do problema a resolver. Em outro instante, fornecemos diretamente os dados do problema e resolvemos sem nenhuma discussão prévia sobre o assunto sem dialogar com os alunos. Com essas nossas atitudes em aulas, causamos dificuldades de aprendizagens e desinteresse em alguns deles. Pois às vezes ficamos sem observar como pensam, sem dar-lhes tempo e chance de resolver algo, porque não dialogamos com eles e resolvemos tudo rapidamente no quadro. Assim, acabamos, provavelmente, deixando alguns alunos para trás, que não conseguem desenvolver com êxito e satisfação suas tarefas, ocasionando com isso um desinteresse pela disciplina de matemática. Ao agirmos como professores de matemática dessa forma, acabamos por ignorar ideias e possibilidades de aprendizagem advogadas por Vygotsky e seus estudiosos 
(COLE, JOHN-STEINER, SCRIBNER, SOUBERMAN, 1978; OLIVEIRA; 1993).

Neste texto trazemos recortes de uma pesquisa de mestrado que investigou o potencial de tarefas de resolução de problemas e de natureza investigativa na aprendizagem matemática deles e também identificou crenças e concepções de estudantes de ensino médio sobre a matemática e seu processo educativo (ROCHA, 2009). O foco deste artigo está em mostrar para outros professores e pesquisadores que tarefas de natureza investigativa oferecem potencial para aulas de matemática no ensino médio. Professores e estudantes passam a perceber que existem outros caminhos para ensinar e aprender matemática além da tradicional aula expositiva de conceitos matemáticos, seguida de exercícios e problemas semelhantes aos resolvidos pelo professor e resolvidos em livros didáticos (SANTOS,1997).

Tarefas matemáticas de natureza investigativa são atividades matemáticas mais abertas, onde nem sempre se coloca uma pergunta inicial, nem se redige um texto como em situações-problema. Entretanto, tais tarefas desafiam os alunos a assumirem um papel ativo em sala de aula e a, de fato, fazerem e aprenderem matemática ao irem agindo como matemáticos (PONTE, OLIVEIRA, CUNHA, SEGURADO, 1998). Ao levar em consideração o próprio conceito de atividade investigativa, não devemos utilizá-la apenas como forma para introduzir ou ensinar conteúdos de matemática, mas também como um modo privilegiado para o aluno desenvolver ações semelhantes às de um matemático. As capacidades de argumentação e prova são dois aspectos destacados da capacidade de comunicar matematicamente (PONTE et al., 1998, p. 16), e essas são características presentes nas atividades de natureza investigativa. Esses autores comentam que o desenvolvimento dessa capacidade é, também, um dos grandes objetivos educacionais do ensino da matemática, segundo o livro Normas para o ensino da matemática (APM [Associação de Professores de Matemática], 1991/1989, [NCTM]).

Para Amorim e Matos (1990), as atividades investigativas deverão ser constituídas de questões abertas, com propostas bem orientadas e exploratórias no início, mas sempre 
mantendo uma margem de liberdade que favoreça, em diferentes níveis, um grau diferenciado de desenvolvimento da aprendizagem. Desejamos que o aluno vá constatando que as ações de um matemático envolvem atividades de formular problemas, levantar hipóteses ou conjecturas, observar padrões e regularidades, procurar generalizar, estabelecer provas ou demonstrações e tirar conclusões. Acreditamos que, dessa forma, podemos proporcionar aos alunos uma aprendizagem com significados e, ao mesmo tempo, propiciar aquisição e construção de conhecimentos de procedimentos matemáticos. Consequentemente, as atividades investigativas devem proporcionar aos alunos a experiência da descoberta, da realização de conhecimento matemático, que é comunicado a uma audiência no seio da qual é discutido (AMORIM \& MATOS, 1990, p.158).

\section{CONTEXTO DO ESTUDO E PERCURSOS METODOLÓGICOS}

Este estudo, de natureza qualitativa, caracterizou-se como uma pesquisa-ação (FIORENTNI: LORENZATO, 2006) que envolveu professores e alunos de uma turma de 34 alunos de primeiro ano de ensino médio da rede pública por cerca de nove meses. Os dados da pesquisa foram coletados em 2008, por meio de aulas observadas e ministradas pelo professor-pesquisador, questionários respondidos pelos alunos de ensino médio e professores, e tarefas resolvidas pelos alunos. Analisamos os dados da pesquisa à luz de autores que trabalham com resolução de problemas (POLYA, 1995/1945; SANTOS, 1997; SANTOS-WAGNER, 2008; SCHOENFELD, 1997/1980); investigação matemática (PONTE, OLIVEIRA, CUNHA, SEGURADO, 1998; PONTE, BROCARDO, OLIVEIRA, 2005), e crenças e concepções (GÓMEZ CHACÓN, 2003; THOMPSON; 1997/1984).

A ideia de explorar o triângulo de Pascal, como tarefa investigativa, surgiu em uma aula em que o assunto abordado era inequações do $2 \circ$ grau. Observamos que alguns alunos erravam exatamente as inequações, no momento em que tinham de desenvolver produtos notáveis, como, por exemplo, resolver a inequação do tipo $(x+4)^{2} \geq 0$. Constatamos que boa parte dos estudantes apresentavam como solução $x^{2}+16 \geq 0$. Ao conversar com eles um pouco sobre a 
resolução desses produtos notáveis, constatamos que muitos não se lembravam de como resolviam esses cálculos algébricos em questão. Foi a partir desses diálogos que tivemos a ideia de fazer uma investigação no Triângulo de Pascal, em que poderíamos investigar com a turma toda como as linhas desse triângulo se relacionam com os coeficientes numéricos dos produtos notáveis.

As etapas que registramos em nossos planejamentos antes da aula investigativa com o triângulo de Pascal foram: (a) Decidimos que, inicialmente, comentaríamos brevemente a respeito da vida e obra de Blaise Pascal, com o objetivo de situarmos os alunos no contexto histórico em que ele viveu e destacar quais foram suas principais contribuições para a ciência. (b) Após essa conversa inicial, colocaríamos na lousa os seguintes produtos notáveis: $(a+b)^{0},(a+b)^{1},(a+b)^{2}$ e $(a+b)^{3}$. Pensamos em desenvolver cada um desses produtos notáveis com a turma. Como está representado na Figura 1, fomos interagindo e dialogando com os estudantes de ensino médio para, juntos, irmos observando se existia ou não uma relação entre os coeficientes numéricos desses produtos notáveis com as linhas do Triângulo de Pascal.

Partimos da ideia de despertar a curiosidade desses alunos e incentivá-los a buscar relações entre esses números que estavam dispostos em forma de um triângulo. Não sabíamos se seria o melhor caminho para ativar a curiosidade deles, mas resolvemos arriscar e, de acordo com o que descrevemos abaixo, parece que deu certo. Os procedimentos para a realização da tarefa foram: (a) copiar o Triângulo de Pascal no quadro para uma melhor visualização; (b) separar as folhas e entregar a primeira folha que chamamos de tarefa 1 , contendo um pequeno texto sobre a vida de Blaise Pascal e os números dispostos formando um triângulo (Anexo I); e (c) solicitar que os alunos executassem as tarefas propostas individualmente. 0 tempo estipulado para essa primeira tarefa foi de 20 minutos. Como já tínhamos trabalhado outra atividade investigativa com números, explicamos que eles deveriam realizar observações livres sobre esses números agora dispostos em forma de um triângulo. Transcorrido o tempo previsto, socializamos as ideias e observações de todos os estudantes 
presentes na aula. Ou seja, no final dessa aula, explorando o Triângulo de Pascal, de forma semelhante ao que aconteceu na primeira tarefa investigativa sobre números, os alunos tiveram um momento para compartilhar suas observações com o grupo e com os professores. Pedimos a um aluno que anotasse no quadro as observações dos colegas.

$\mathrm{Na}$ segunda aula, durante a execução da tarefa 2, fizemos algumas perguntas que direcionavam o foco de atenção dos estudantes para observações bem pontuais sobre o Triângulo de Pascal. O objetivo era motivá-los a validar algumas conjecturas. O tempo estipulado para essa tarefa foi de 25 minutos. Durante o desenvolvimento da atividade, percebemos que a ideia de mostrar-Ihes a relação do Triângulo de Pascal com os produtos notáveis funcionou. Esse fato foi constatado a partir de seus olhares e das perguntas que surgiam durante nossa explicação dos produtos notáveis e sua relação com esses cálculos algébricos. Observamos que eles estavam interessados por aquilo que estávamos falando.

Figura 1. Relações observadas entre os coeficientes numéricos dos produtos notáveis e o Triângulo de Pascal.

\section{Produtos Notáveis}

$(a+b)^{0}=1$

$(a+b)^{1}=1 a+1 b$

$(a+b)^{2}=1 a^{2}+2 a b+1 b^{2}$

$(a+b)^{3}=1 a^{3}+3 a^{2} b+3 a b^{2}+1 b^{3}$

\section{Triângulo de Pascal}

1

11

$1 \quad 2 \quad 1$

$\begin{array}{llll}1 & 3 & 3 & 1\end{array}$

Fonte: dados da pesquisa

Com o caminhar da pesquisa e com a atividade realizada no início com números, constatamos que alguns alunos iniciaram as observações sem mesmo fazermos algum pedido. No final das duas tarefas dessa investigação matemática com o triângulo, os alunos reclamaram a respeito do tempo destinado a cada tarefa, alegando que não era suficiente. Eles gostariam de ter mais tempo para realizar suas observações, formular hipóteses e tirar conclusões, pois sinalizaram que essa foi a fase de que mais gostaram quando realizaram a tarefa investigativa anterior com números.. 


\section{RESULTADOS E DISCUSSÕES}

A experiência adquirida com a realização da primeira tarefa investigativa com números fez com que essa segunda tarefa de investigação matemática ficasse mais simples de ser conduzida. Conseguimos observar um maior envolvimento dos alunos em todas as etapas da tarefa, ou seja, na fase de observação, registro e validação de suas conjecturas. A seguir, passamos a descrever com mais detalhes os procedimentos realizados por três estudantes na pesquisa de mestrado de Rocha (2009), ao explorar o Triângulo de Pascal. Entretanto, de início destacamos cinco constatações a respeito do comportamento da turma nessa segunda tarefa investigativa:

i) Os 30 estudantes presentes, como um todo, revelaram estar mais familiarizados com esse tipo de tarefa matemática, por meio da qual deveriam procurar investigar e observar regularidades, registrar o que identificaram na tarefa, formular hipóteses e conjecturas, procurar alguma forma de explicar o que observaram, registraram e conjecturaram. Nessa segunda tarefa investigativa, os alunos solicitaram em poucos momentos a ajuda do professor;

ii) No momento de discussão acerca de suas conjecturas, alguns alunos revelaram ter melhorado a capacidade de comunicar suas ideias, por escrito e oralmente, e as conclusões obtidas;

iii) Os estudantes solicitaram menos a presença do professor para validar suas observações quando estavam trabalhando em pequenos grupos. Entretanto, observamos, durante a socialização com a turma, que algumas afirmações e conjecturas que foram apresentadas não eram válidas, ou seja, eles não conseguiram validar algumas das afirmações apresentadas;

iv) Um número reduzido de alunos demonstrou ter espírito crítico face às conclusões 
apresentadas por outros colegas durante a fase de validação das conjecturas. Foi preciso incentivá-los a perguntar mais sobre as observações e registros apresentados por cada um dos grupos;

v) A maior parte dos estudantes, ainda, não conseguiu compreender que, se uma conjectura serve para alguns casos, não significa que servirá para todos os outros casos. Mesmo assim, observamos alguns alunos demonstrando certo interesse em validar suas conjecturas com certos argumentos.

\section{Papéis do professor pesquisador e dos estudantes na realização dessa tarefa}

Como essa era a segunda atividade de natureza investigativa, que trabalhamos com a turma, continuamos assumindo um papel relevante ao conduzir diálogos com os discentes e ao organizar informações no coletivo ao final da fase de observações e registros iniciais (cf. PONTE et al., 1998; PONTE, BROCARDO, OLIVEIRA, 2005). Mas, já observamos algumas mudanças no comportamento dos estudantes, individualmente e em grupos, pois conseguiram prosseguir com a resolução da tarefa quase que sozinhos durante a fase de observações. Apenas alguns grupos solicitaram nossa ajuda para validar suas conjecturas, mas nenhum grupo teve dificuldade em realizar a parte inicial da tarefa investigativa.

Acreditamos que esse processo inicial de reconhecer as particularidades de uma tarefa investigativa e de aceitar que devem trabalhar mais independentes do professor e de que a tarefa tem um cunho mais aberto já foi superado. Enfim, os estudantes entenderam que eles devem preocupar-se em observar detalhes, padrões e regularidades matemáticas e registrar suas hipóteses, compreenderam que essa tarefa fica sem trazer uma pergunta ou perguntas para responder inicialmente. Eles já sabiam, nessa etapa, que, em tarefas investigativas, como as realizadas com os números, não ficariam somente a procurar uma resposta única para um determinado problema, pois precisavam formular problemas e pensar em como resolvê-los. 
Parece-nos que essa fase de estranhamento, pelo cunho aberto das tarefas investigativas, em contraponto ao cunho fechado de problemas ou exercícios matemáticos rotineiros, já tinha sido superada pela turma. O nosso principal papel foi o de um professor que auxiliava os alunos a focalizar atenção nos objetivos centrais da tarefa; observava atentamente os estudantes; dialogava com eles quando necessário; fazia questionamentos que os levassem a pensar e, enfim, atuava como um condutor de uma orquestra ao final dessas diversas fases. Em síntese, tivemos também que: i) Recordar certos conteúdos de matemática importantes para a realização da tarefa; ii) Sentar junto aos grupos para incentivá-los cada vez mais a procurarem outras regularidades; e iii) Conduzir os debates e as tentativas de eles mostrarem a validade de conjecturas durante a apresentação dos grupos. Em aulas de investigação, o papel do professor, como mediador, é fundamental, pois, segundo Ponte, Brocardo e Oliveira (2005):

Existe, por vezes, a ideia de que, para que o aluno possa, de fato, investigar, é necessário deixá-lo trabalhar de forma totalmente autônoma e, como tal, o professor deve ter somente um papel de regulador da atividade. No entanto, o professor continua a ser um elemento-chave mesmo nessas aulas, cabendo-lhe ajudar o aluno a compreender o que significa investigar e aprender a fazê-lo (p. 26).

Portanto, devemos ressaltar a importância do papel do professor como mediador nesses momentos iniciais, principalmente quando a turma tem pouca ou nenhuma experiência com essas atividades investigativas. Procuramos, nessa investigação matemática com o Triângulo de Pascal, desempenhar esse papel, e percebemos que essas tarefas têm potencial para envolver e motivar estudantes de ensino médio em aulas de matemática. Mostramos, a seguir, as respostas de três estudantes quando resolveram essa tarefa investigativa, para comentarmos e analisarmos relações matemáticas que eles fizeram. Na primeira parte da tarefa, informamos o seguinte aos estudantes da turma de primeiro ano de ensino médio: "Procure descobrir relações entre os números acima, registre as conclusões que for obtendo". Iniciamos com as observações feitas pelo estudante A9. Também inserimos os registros dele 
sobre tudo que observou e descobriu ao olhar para os números organizados em linhas e colunas no Triângulo de Pascal.

Figura 2. Observações do estudante A9.

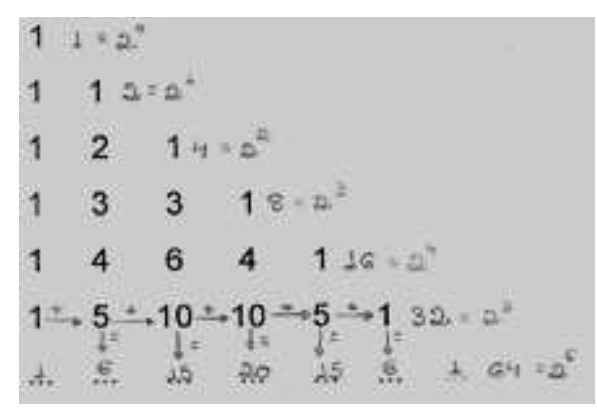

Fonte: dados da pesquisa.

Na segunda parte da tarefa investigativa com o Triângulo de Pascal, foi solicitado aos estudantes o seguinte: "Justifique o processo de construção das linhas". Mostramos a seguir, as informações registradas pelo estudante A9.
a) Sempre há um número 1 nos extremos;
b) A 2a coluna segue uma ordem consecutiva, começando no número 1;
c) A cada nova linha se acrescenta um algarismo;
d) A 2a transversal de cima para baixo também está em ordem consecutiva;
e) A soma das linhas é o dobro da soma da linha anterior;
f) A soma das linhas está em ordem crescente de potências de base 2, sendo que a $1^{\text {a }}$ é $2^{0}$, a $2^{\text {a }}$ é $2^{1}$, e assim sucessivamente.

Figura 3. Justificativa do estudante A9.

\begin{abstract}
1) Explique como podemos escrever novas linhas desse Triângulo, utilizando os valores da(s) linha(s) anterior(es).
\end{abstract}

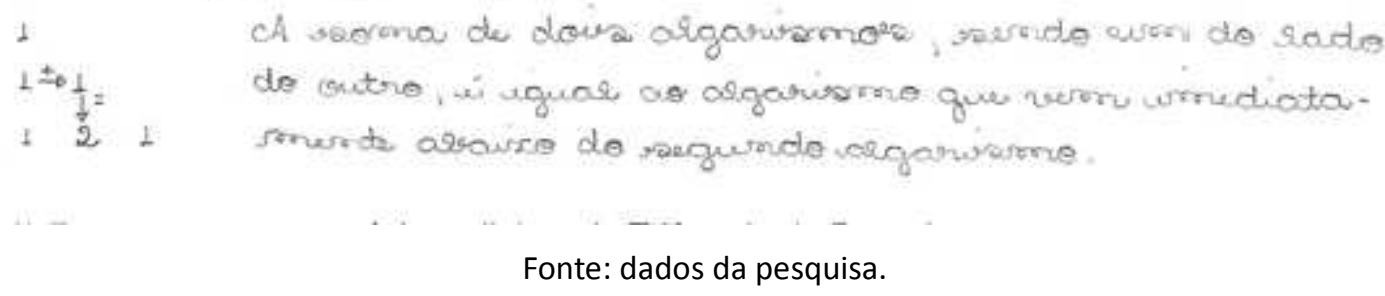


O estudante A9 teve dificuldades de explicitar seu pensamento em palavras, mas sabia como obter outras linhas, pois, inclusive, calculou todos os elementos que estariam na sétima linha do triângulo na figura 2. O argumento dele, para explicar que cada número da nova linha é formado pela soma de outros dois números da linha anterior, ficou mais claro quando ele utilizou os símbolos $\rightarrow$ e + conforme vemos na figura 2 . De qualquer forma, é sempre importante observar que os alunos procuraram utilizar vários recursos ao tentar justificar suas respostas, seja em linguagem com símbolos matemáticos ou em linguagem corrente. Ficamos satisfeitos ao constatar que esse estudante $A 9$ já estava com um olhar mais refinado e criterioso ao observar os números e encontrar regularidades matemáticas. Esse aluno desempenhou seu papel como aluno ativo nessa aula e procurou pensar por si mesmo na procura das regularidades (PONTE et al, 1998).

$\mathrm{Na}$ fase final da tarefa, o estudante deveria generalizar uma conjectura que tivesse feito a partir do que observou e levantou de hipóteses ao investigar linhas e colunas no Triângulo de Pascal. Ou seja, solicitamos aos estudantes: Generalização de uma conjectura. Vejamos, a seguir, como o estudante A9 explicou, em palavras, como seria seu procedimento geral para encontrar a soma de qualquer linha.

Figura 4. Generalização do estudante A9.

2) Procure estabelecer uma relação ( ou fórmula) para encontrar a soma de qualquer linha desse triângulo.

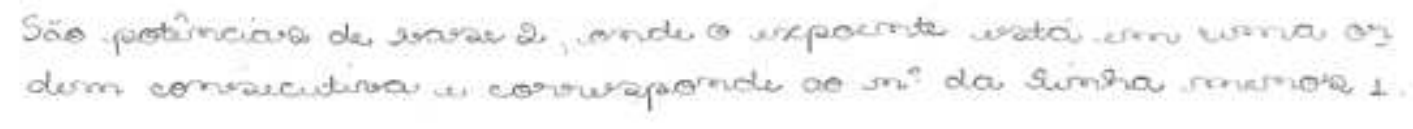

Fonte: dados da pesquisa.

\section{Interpretações das respostas e pensamentos do estudante A9}

Esse estudante registrou observações que foram comuns a outros colegas da turma, como por exemplo, o número 1 aparece em todos os extremos, a soma das linhas é o dobro da soma da linha anterior; na segunda coluna, segue uma ordem consecutiva, começando no 
número 1. Gostaríamos de destacar que as observações feitas na primeira atividade com números influenciaram boa parte dos alunos. Praticamente todos os alunos passaram a procurar regularidades e a buscar padrões matemáticos que envolvessem somas, produtos ou outros cálculos matemáticos. Notamos que eles já faziam somas e relacionavam os resultados. O estudante A9 nos mostrou, com suas observações e registros, como ele procurava identificar relações matemáticas entre essas somas (PONTE, BROCARDO, OLIVEIRA, 2005). Verificamos, em seus registros na Figura 2, que ele escreve todos os elementos numéricos que comporiam a sétima linha do triângulo de forma independente, e isso nem era solicitado. Ou seja, ele calculou esses elementos e demonstrou que buscava generalizar matematicamente a forma de escrever as linhas subsequentes. É um aluno que demonstrou domínio da linguagem matemática e quase conseguiu descrever de maneira clara, em linguagem corrente, suas conclusões nos dois questionamentos dados.

\section{Registros do estudante A13 para essa tarefa investigativa}

$\mathrm{O}$ estudante $\mathrm{A} 13 \mathrm{fez}$ os seguintes registros a respeito do que observou no triângulo de Pascal e de como foi percebendo que os números apareciam nas linhas e colunas. De forma semelhante ao estudante $A 9$, o estudante $A 13$ registrou suas observações assim:

a) Na segunda coluna há uma sequência de números de 1 em 1 ;

b) Os números que estão nas linhas, começando do 1 ao 14641, são as potências do número 11 , veja: $11^{0}=1,11^{1}=11,11^{2}=121,11^{3}=1331 \mathrm{e}$ $11^{4}=14641$

c) A primeira coluna repete sempre o número 1, e, na última transversal à direita, também aparece somente o número 1 ;

d) Na segunda transversal, há uma sequência de 1 em 1 em sequência;

e) As transversais vão se repetindo nas colunas em número e ordem;

f) Há uma soma dos números acima para obtermos os números abaixo. 
Figura 5. Observações do estudante A13.

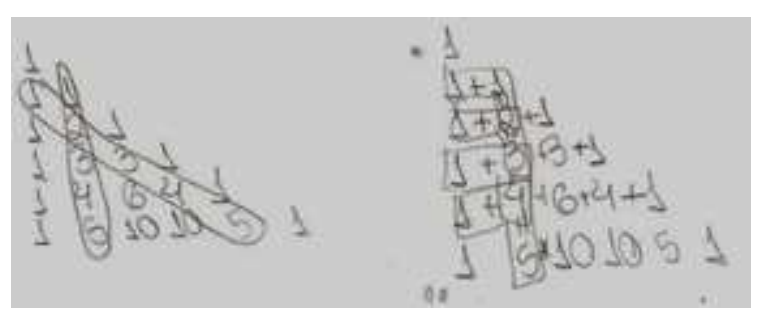

Fonte: dados da pesquisa.

Foi muito interessante ler esses registros e observações do estudante $A 13$, e ele foi o único estudante dos 30 presentes nessa aula que constatou alguma relação entre os números dispostos nas linhas do Triângulo de Pascal e as potências de 11 (PONTE; BROCARDO, OLIVEIRA, 2005). Foi muito rica a etapa de compartilhar ideias no coletivo, quando o aluno A13 trouxe suas observações. Para justificar o processo de construção das linhas, trazemos a seguir um recorte da resposta de A13. De modo diferente dos registros feitos pelo aluno A9 ao lado dos números que estavam arrumados no triângulo, o aluno A13 vai mostrando com registros visuais suas observações e conclusões na figura anterior. Sua explicação, em palavras, sobre como escrever a linha seguinte ficou pouco clara. Mas provavelmente isso é o que esse estudante conseguiu externar em uma segunda experiência com tarefas matemáticas de natureza investigativa. Por outro lado, o olhar matemático desenvolvido por esse estudante foi surpreendente.

Figura 6. Justificativa do estudante A13.

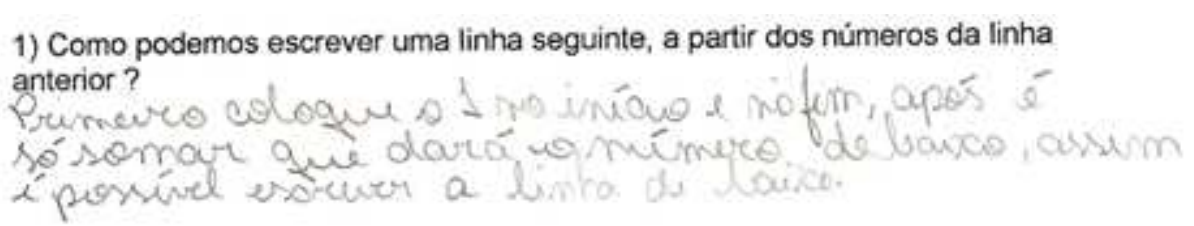

Fonte: dados da pesquisa.

$\mathrm{Na}$ fase final da tarefa, quando incentivamos os estudantes a generalizarem suas conjecturas, observamos o estudante A13 escrevendo direto uma fórmula sem nos mostrar nem como pensou sobre a mesma nem como chegou a ela. Ele também não nos deu pistas claras de que saberia validar essa conjectura. De qualquer modo, ele conseguiu detectar detalhes 
matemáticos que seus colegas não tinham percebido. Além disso, eles não estavam habituados, antes dessas aulas, a ter que verbalizar ou explicar, em palavras, como pensavam e resolviam tarefas matemáticas.

Figura 7. Generalização do estudante A13.

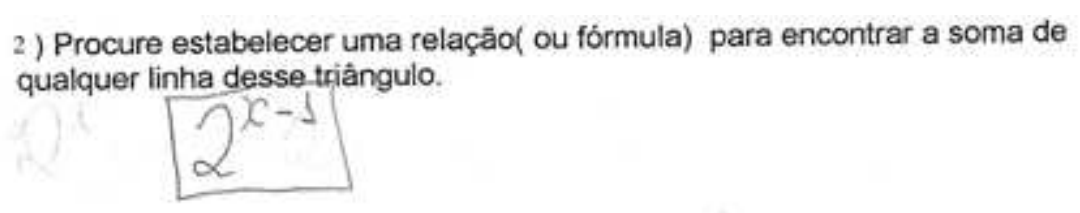

Fonte: dados da pesquisa.

\section{Interpretações e comentários das respostas do estudante A13}

Verificamos que algumas de suas observações foram semelhantes às do estudante A9 no momento em que comenta acerca da localização do 1 no triângulo, e quando efetua algumas somas para projetar os elementos de uma outra linha. Entretanto, gostaríamos de destacar uma observação bem criativa desse aluno, quando relata que identificou que, de 1 ao 14.641, tinha encontrado as potências do número 11 . Ou seja, o olhar matemático de A13 para encontrar e testar regularidades matemáticas estava bem mais ativo do que antes de termos explorado atividades investigativas em aulas.

Acreditamos que alguns estudantes dessa turma começaram a ter um olhar mais criterioso em atividades matemáticas e desenvolveram algumas observações que não são de alunos de ensino médio que simplesmente buscam resolver questões, encontrar respostas prontas e informações simples. O aluno A13 estava desenvolvendo um olhar matemático para as tarefas, como os autores sugerem, ao relatar sobre tais tarefas (PONTE et al., 1998; PONTE, BROCARO, OLIVEIRA, 2005). Esse fato demonstra que esse aluno possui um olhar mais crítico quando desenvolve uma atividade investigativa na procura de regularidades numéricas. Quando tenta justificar a formação da linha seguinte do triângulo, em que diz "Primeiro coloque o 1 no início e no fim, após é só somar que dará o número de baixo, assim é possível escrever a linha de baixo", ele não deixa claro que seria a soma dos números da linha anterior, mas quando recorremos aos seus registros visuais na figura 5 , compreendemos que 
está dizendo que seria a soma dos números acima. No momento em que tenta estabelecer uma relação matemática para encontrar a soma dos elementos de qualquer linha desse triângulo, ele simplesmente escreve a fórmula sem nenhuma justificativa. Acreditamos que seja pelo fato de o enunciado em questão dizer que poderia ser simplesmente uma fórmula. Pedimos para que ele tentasse justificar, mas ele não relatou nada. Assim, ficamos sem saber como ele pensou e como se convenceu de que essa fórmula funcionaria.

\section{Registros do estudante A30 para essa tarefa investigativa}

a) 0 triângulo em volta só tem número 1 ;

b) Da mesma forma que na segunda linha (vertical) os números se seguem $1,2,3 \ldots$ na segunda transversal acontece o mesmo.

\section{Justificando o processo de construção das linhas}

01) Como podemos escrever uma linha seguinte, a partir dos números da linha anterior?

Figura 8. Justificativa do estudante $A 30$

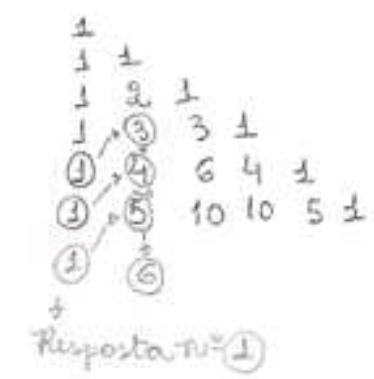

Fonte: dados da pesquisa.

\section{Generalizando uma conjectura}

Figura 9. Generalização do estudante A30 


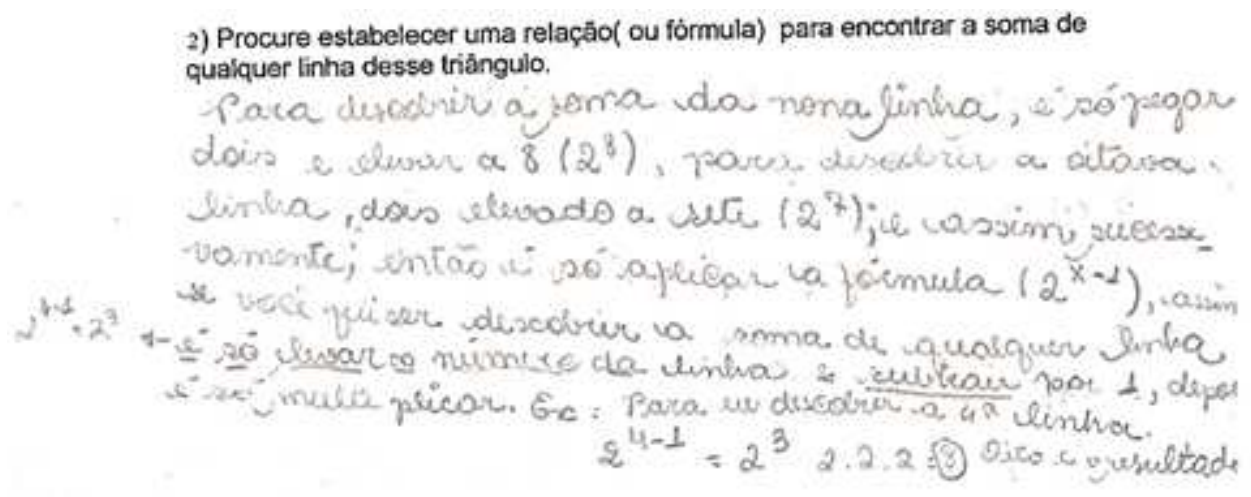

Fonte: dados da pesquisa.

\section{Interpretações e comentários das respostas do estudante A30}

Esse aluno fez poucas observações na primeira tarefa. Ele sinalizou informações simples como a presença do número 1 em volta do triângulo e que existe uma sequência de números em cada horizontal e que, na segunda vertical, ele observou a sequência de números 1,2 , 3 ... que vai aparecendo nessa vertical. Quando tentou generalizar, recorreu a um desenho para justificar que, somando alguns números, seria possível escrever outros números. Entretanto, se verificarmos, a partir do seu desenho, como usaria esse raciocínio para encontrar outros números, podemos perceber que ele não conseguirá escrever todos os elementos de cada linha da forma como ele propõe essa soma.

Quando analisamos a segunda pergunta sobre a soma dos elementos de uma linha, percebemos que ele começa atribuindo valores numéricos, procurando justificar os resultados obtidos até caracterizar a fórmula $2^{x-1}$. Esse aluno não fez uma demonstração formal utilizando recursos algébricos mais complexos. Na verdade, ele começou testando a veracidade da afirmativa com base apenas em testagem de alguns casos particulares. As autoras Nasser e Tinoco (2003, p. 4) chamam esse tipo de estratégia de justificativa pragmática. Mas vale a pena destacar que esse aluno, A30, assim como o A13, conseguiram ir buscando mais detalhes e regularidades numéricas do que outros estudantes da turma. Esses dois iniciaram a olhar para essa tarefa com um olhar matemático, procurando encontrar pistas que pudessem testar e experimentar. E, de fato, em cada linha do triângulo de Pascal, vai ser possível identificar a soma dos números que aparecem nessa linha 
pensando em calcular $2^{\mathrm{x}-1}$, em que $\mathrm{x}$ representa a linha do Triângulo de Pascal. $\mathrm{O}$ aluno A30 ficou sem saber como demonstrar que esse cálculo vai dar sempre certo e que, assim, ele pode encontrar a soma dos termos numéricos da terceira linha como sendo $2^{2}$, ou seja, a soma dos termos da terceira linha pode ser escrita como:

Soma 3a linha: $1+2+1=4=2^{2}$

$\mathrm{E}$, assim por diante, ele observou que:

Soma 4a linha: $1+3+3+1=8=2^{3}$

Soma 5a linha: $1+4+6+4+1=16=2^{4}$

De fato, o aluno A30 ainda precisava provar matematicamente que essa observação vai valer para a soma dos elementos numéricos de qualquer linha desse triângulo de Pascal. Mas esse tipo de raciocínio de prova matemática era completamente novo para os estudantes dessa turma de primeiro ano de ensino médio. Ficamos satisfeitos de ter alunos diferentes dessa turma já com um olhar matemático acurado e encontrando regularidades numéricas importantes nos números dispostos no triângulo de Pascal. Isso corrobora os argumentos de Ponte, Oliveira, Cunha e Segurado (1998) e, mais recentemente, de Ponte, Brocardo e Oliveira (2005) e Fernandes, Fiorentini e Cristovão (2006) a respeito do potencial motivador, do desenvolvimento de criatividade e do engajamento matemático dos alunos em tarefas investigativas.

Quando iniciamos alguns estudos sobre atividades de natureza investigativa, percebemos que alguns colegas diziam que não trabalhavam com esse tipo de atividade de cunho aberto, porque ficava muito difícil limitar o conteúdo matemático a ser abordado. Disseram ainda que, dependendo do desenrolar da atividade, isso poderia atrasar os conteúdos que são propostos pela escola. Acreditamos que isso vai depender do professor, de sua motivação para experimentar e arriscar outros procedimentos de ensino, e de suas crenças e concepções a respeito de matemática e seu processo educativo (THOMPSON, 1997/1984), 
porque, quando o professor se propõe a adaptar uma atividade a sua realidade escolar, ele poderá desenvolver o trabalho sem nenhuma sombra de dúvida, mesmo que ocorram dificuldades e momentos para refletir e rever os procedimentos pedagógicos. Ao finalizar essa atividade com Triângulo de Pascal, podemos dizer que, dentre os conteúdos que exploramos sobre potenciação e produtos notáveis, notamos potencialidade em trabalhar com: função exponencial, logaritmos, progressões aritméticas, geométricas e outros. Talvez fosse interessante ter trabalhado uma atividade investigativa que abordasse outros ramos da matemática, como: geometria, estatística ou probabilidade. Dessa forma, poderíamos verificar como seriam os resultados dos alunos frente a esses outros ramos da Matemática. Mas, como estávamos tentando adaptar as atividades aos conteúdos que estavam sendo abordados, decidimos aplicar outra atividade com números.

\section{Conversando com alguns alunos sobre aulas com tarefas investigativas}

Por acreditarmos que é necessário ouvir a opinião dos alunos sobre a realização das atividades de natureza investigativa, solicitamos que eles escrevessem sobre o trabalho realizado com essas atividades. Realizamos uma entrevista com a turma sobre as atividades investigativas de números e de triângulo de Pascal. Nessa entrevista, fizemos os seguintes questionamentos aos alunos:

1) Durante o desenvolvimento das atividades investigativas, de que você mais gostou? Por quê?

2) Durante o desenvolvimento das atividades investigativas, de que você menos gostou? Por quê?

3) Quando você teve que apresentar suas conclusões, como você se sentiu? Por quê?

4) Em que as atividades investigativas influenciaram a sua aprendizagem de matemática? Por quê?

Ler, reler e examinar as respostas dos 34 alunos da turma de primeiro ano de ensino médio foi permitindo entender um pouco da ligação entre a parte afetiva e cognitiva dos alunos 
durante essas aulas bem diferentes do que geralmente é trabalhado em aulas de matemática (GÓMEZ CHACÓN, 2003). Sabemos que precisamos conhecer nossos alunos, escutar nossos alunos (LORENZATO, 2006) e compreender como se sentem ao desenvolver atividades matemáticas rotineiras e também ao resolveram tarefas bem abertas e diferentes como essas investigações matemáticas (GÓMEZ CHACÓN, 2003; PONTE et al., 1998). Vamos destacar alguns comentários feitos pelos alunos dessa turma de ensino médio a respeito da realização das atividades investigativas, tentando não categorizar suas respostas, mas com o objetivo de organizá-las de forma a compreender um pouco o impacto dessas tarefas nos alunos. Assim, após várias leituras das respostas, procuramos ir identificando os temas emergentes para agruparmos ou categorizarmos parte das respostas. A partir da ideia do trabalho de Cristovão, Fernandes e Fiorentini (2006), adaptamos algumas categorias que eles usaram e que estavam de acordo com nossas leituras e agrupamentos iniciais das respostas ou parte delas. Pensamos em agrupar nossas respostas e trechos das respostas em três bloco que apresentamos a seguir.

\section{Afirmações que fornecem indícios de preocupação com o conteúdo programático}

A1 - O que não gostei, acho que é de girar muito tempo numa mesma questão! Mas é bom porque cada vez tentamos descobrimos mais coisas. A6 - Há! Acho que é de ficar muito tempo numa mesma questão! Mas é bom porque cada vez que tentamos descobrimos mais coisas.

A7 - Achei que algumas aulas demoravam muito com o mesmo conteúdo, como não sei se o ano que vem vamos continuar, acho que seria interessante juntar investigação com os conteúdos que devemos estudar.

A9 - O aluno não trouxe em suas respostas preocupação com o conteúdo programático.

A13 - O que não gostei era quando as aulas não rendiam tanto quanto outras.

A23 - Acho que é tentar provar o nosso resultado. Isso demorava mais e ficávamos sempre no mesmo conteúdo.

A30 - Fiquei com medo de não dar para responder tudo, pois sempre precisava ler várias vezes para entender (estava um pouco complicado 
relacionar com a matéria que estávamos estudando).

Observamos uma preocupação dos alunos em relação aos conteúdos e ao tempo que destinamos às aulas de investigação. Verificamos que, mesmo conversando com eles sobre o desenvolvimento das atividades e quais conteúdos matemáticos foram abordados, nem todos se convenceram disso. Constatamos, nas respostas dos alunos acima e de outros da turma, que alguns alunos não conseguiram compreender que esse tipo de atividade leva mais tempo em sala de aula, mas que seguem aprendendo matemática. Parece que nem todos os alunos compreenderam ou observaram que, nas aulas com investigação matemática, eles são desafiados de outra forma e conseguem desenvolver outras habilidades como observação de regularidades numéricas, argumentação e generalização. Também ficaram sem perceber que essas habilidades não são comuns e não são desenvolvidas em uma aula de matemática tradicional e rotineira, em que só corrigimos exercícios e problemas semelhantes aos do professor e do livro didático.

\section{Afirmações que parecem apontar dificuldades e falhas durante a execução das atividades}

A1 - Achei complicado quando, além de observar, tinha qe explicar e provar. A6 - Ficava sempre com um pé atrás porque às vezes não sabia o que deveria encontrar.

A7 - No início com as atividades, eu não estava entendendo nada do que os professores explicavam, e para mim aquilo tudo não fazia sentido nenhum. A9 - A interferência de alguns alunos quando tentava observar algo.

A13 - Quando recebi a atividade, fiquei espantado, porque nunca havia visto coisas tão complicadas juntas, mas foi só a aparência.

A23 - O aluno não trouxe em suas respostas indícios de dificuldades na execução das atividades investigativas.

A30 - Um frio na barriga, porque achei que não tiraria conclusões nenhuma, e nem perceberia nada de diferente do que meus colegas estavam percebendo.

Quando iniciamos os trabalhos com investigação matemática, pretendíamos deixar os alunos 
bem à vontade, no sentido de incentivá-los a viajarem de forma livre em suas mentes na busca de observação. Deixamos que as primeiras discussões acontecessem em grupos pequenos, e talvez algum aluno tenha influenciado nas observações dos outros. Percebemos, também, que, durante as primeiras atividades, os alunos ficavam realmente perdidos, e sem saber o que fazer, pelo fato de nunca terem experimentado antes esse tipo de aula. Mais uma vez revimos os trabalhos dos colegas portugueses que iniciaram os trabalhos com investigações matemáticas e entendemos por que sugerem que os professores se preparem para essas aulas e que conversem com os alunos (PONTE et al., 1998; PONTE; BROCARDO, OLIVEIRA, 2005).

Refletimos, também, após esse estudo de nove meses com resolução de problemas e tarefas investigativas, sobre o fato de que, para os alunos, aconteceram muitas novidades nas rotinas das aulas de matemática deles no ensino médio. Foi muita novidade em termos de papel de aluno e de professor em aulas e nos tipos de tarefas em aula, como comenta Santos (1997), ao falar de aulas tradicionais e aulas inovadoras. Ademais, para os alunos, mudou todo o cenário e roteiro da aula, pois passaram de aulas em que os exercícios e os problemas já dizem o que fazer e como fazer e passaram para tarefas mais abertas como as investigativas. Nessas novas tarefas investigativas, os alunos, individualmente ou organizados em pequenos grupos, precisam aprender a se colocar no papel de um matemático, propondo problemas, observando detalhes e regularidades matemáticas e, depois, ainda experimentarem o desafio de pensar em como argumentar e provar o que colocaram como conjectura.

\section{Afirmações que valorizam o trabalho com natureza investigativa e parecem trazer intrínsecos os próprios objetivos das aulas investigativas}

A1 - É muito diferente e legal. Parece que as aulas passavam mais rápido, porque, a cada aula, nós descobríamos algo diferente, algo que ficamos estudando o tempo todo e, às vezes, já havíamos decorado como resolver, mas não sabíamos o porquê. Por isso, foi interessante tentar provar os nossos resultados. 
A6 - Essas atividades investigativas me influenciaram na aprendizagem dos teoremas e a desenvolver processos e meios de avaliar diversas situações, porque é divertido descobrir as coisas sozinho, é mais prazeroso.

A7 - O incentivo que o professor nos dava para aprender coisas que não víamos no primeiro momento em certas atividades. $\mathrm{E}$ quando compartilhávamos nossos resultados como os colegas, eles nos ajudavam e compreender nossos erros.

A9 - Durante as atividades, percebi que devo resolver os processos por partes e trabalhar primeiramente com as informações que me foram dadas. A13 - Essas aulas me influenciaram em fazer com que nós "treinássemos" nossa percepção de ver coisas invisíveis a olho nu. Assim, durante problemas matemáticos, conseguimos ver coisas que não víamos antes. 0 que mais gostei foi de forçar a mente para descobrir as respostas, pois em uma aula normal você não força tanto a mente, por que você já sabe a matéria que vai usar, e quando você tem que explorar parece que forçamos mais a mente.

A23 - De ser igual a um detetive, enquanto não investigar tudo, até achar o bendito dos números, não desistia.

A30 - Melhorei bastante meu modo de pensar sobre a Matemática. Na hora de responder qualquer atividade, eu passei a querer entender, saber por que era assim, por que tinha que dar aquilo, etc.

Analisando essas informações que os alunos expuseram, conseguimos detectar, nos depoimentos deles, que alguns dos objetivos das atividades investigativas foram atingidos, como a elaboração de conjecturas, refinamento das questões, demonstração e comunicação dos resultados obtidos. As respostas desses alunos trazem indícios de que, para eles, mesmo esse número reduzido de duas atividades de natureza investigativa que realizamos com a turma, houve impacto no processo de aprendizagem de matemática e nas estratégias que eles usam quando se deparam com tarefas matemáticas. Para Pontes, Brocardo e Oliveira (2005), o envolvimento ativo do aluno é condição fundamental da aprendizagem. O educando aprende quando mobiliza os seus recursos cognitivos e afetivos com vistas a 
atingir um objetivo.

\section{CONCLUSÕES E REFLEXÕES}

Ao trabalhar em aulas de matemática com atividades investigativas e de resolução de problemas em que os alunos não ficam presos aos algoritmos, às equações e aos teoremas, eles trocam ideias entre si e questionam mais o professor. Esses procedimentos de diálogos e questionamentos favorecem que os alunos façam reflexões a respeito dos temas explorados nessas tarefas, e isso os ajuda na compreensão do assunto. Observamos que tem sido produtivo propor aos alunos atividades e problemas que deixem de ter o intuito apenas de achar a solução para um problema, ou várias soluções para um mesmo problema, usando algoritmos, fórmulas e teoremas já vistos anteriormente. É por essas razões que temos alterado a prática em sala de aula, em busca de ações mais criativas que favoreçam discussões em grupo e análise sobre o papel de cada um, professor e aluno, na realização das atividades. Também temos verificado na prática que essas formas alternativas de trabalhar com a matemática no ensino médio permitem que alunos desenvolvam raciocínios e estratégias matemáticas num processo mediado pelos diálogos e reflexões entre alunos e professor, como preconiza a teoria de Vygotsky, e assim aprendam conceitos matemáticos de forma semelhante aos matemáticos (COLE, JOHN-STEINER, SCRIBNER, SOUBERMAN, 1978; OLIVEIRA; 1993).

Em conclusão, na introdução das primeiras atividades investigativas, os alunos manifestavam uma grande dependência do professor, mas conseguiram evoluir e se tornaram mais independentes. Tudo que realizamos nessa pesquisa de mestrado foi na tentativa de compreender o que aconteceria em uma turma de 1으 ano de ensino médio quando as aulas de matemática fossem trabalhadas usando modelos de ensino que não fossem apenas o modelo tradicional. Além disso, procuramos compreender como os alunos reagiriam ao trabalhar com algumas situações de resolução de problemas e atividades de natureza investigativa. Mudanças ocorridas no comportamento e na aprendizagem dos discentes 
foram evidenciadas pelo papel diferenciado que passaram a assumir, tendo que compreender que não lhes seriam dirigidas perguntas diretas, mas sim propostas situações mais abertas, em que eles tinham que observar, registrar, interpretar, analisar e validar suas conclusões.

Consideramos, portanto, que eles desenvolveram alguma autonomia em relação ao professor. Evidenciamos uma melhoria gradativa na forma de comunicar suas ideias quer seja oralmente ou por escrito. Os alunos foram adquirindo certa criatividade e destreza na procura por determinados padrões e relações numéricas. Dentre os vários exemplos, podemos citar, quando o aluno A13 evidencia que, nas quatro primeiras linhas do Triângulo de Pascal, os resultados representam as potências de base 11 , ou seja, $1=11$ 으, $11=111,121$ $=112,1331=113$ e que $14641=114$. Esse aluno demonstrou certo refinamento em suas observações, uma vez que esse mesmo aluno, nas primeiras atividades, fez observações relativamente simples e sempre em consonância com os demais colegas. Parece-nos que, em particular, esse aluno conseguiu assumir um papel de matemático ao trabalhar com essa tarefa e passou a investigar buscando encontrar um determinado padrão matemático.

Percebemos que, à medida que íamos desenvolvendo as atividades investigativas, tanto os alunos, quanto nós, professores, diminuímos nosso receio em trabalhar com questões tão abertas. Observamos um aprendizado e um aperfeiçoamento no modo de trabalhar em grupo, principalmente nos momentos em que cada grupo apresentava suas conclusões (SANTOS, 1997). Foi possível entender que o trabalho investigativo, dando liberdade ao aluno, permite que ele escolha formas de agir autônomas e que sua referência será o limite de seus conhecimentos e o modo como se envolve na busca de suas observações. Assim, constatamos que os alunos ficam mais seguros para trabalhar com atividades que sejam as mais livres possíveis, que não limitem sua linha de ação e observação. Verificamos isso no momento em que aplicamos a primeira atividade com números, pois simplesmente eles fizeram as observações livres (ROCHA, 2009). 
Já na segunda atividade, com o Triângulo de Pascal, que abordamos neste texto, percebemos que alguns alunos não estavam conseguindo justificar as generalizações que solicitamos. Mas já conseguiam, de modo independente, observar e registrar diversas regularidades e padrões matemáticos. Apesar de os estudantes terem desenvolvido habilidades de observar, estabelecer relações, formular conjecturas e argumentações e dar evidências de criatividade nessas aulas, identificamos, entretanto, muitos ainda com dificuldades para validar suas conjecturas. Avaliamos que a etapa de validação de conjecturas foi a mais difícil de ser realizada em sala de aula. Talvez devêssemos ter trabalhado primeiro com tarefas investigativas mais simples, e então levá-los a tentar justificar e validar suas próprias conjecturas em situações mais diretas. Em alguns momentos, observamos que era exigido dos alunos um grau de abstração superior ao que eles eram capazes naquele momento no ensino médio. Notamos, quando eles apresentavam suas conclusões, que alguns ainda não conseguiam identificar a diferença entre verificar conjecturas para casos particulares e verificar se seria possível mostrar a validade delas para outros casos mais gerais. Mesmo assim, alguns alunos demonstraram maior confiança durante a etapa de elaboração de estratégias, análise de resultados e resolução de problemas e também na hora de comunicar suas ideias matematicamente.

\section{REFERÊNCIAS}

(espaçamento simples, com 0,20 cm depois do parágrafo)

AMORIM, I.; MATOS, J. F. Actividades investigativas em matemática: porquê, para quê, como? Em: ENCONTRO DE PROFESSORES DE MATEMÁTICA, 1990, Caldas da Rainha, ACTAS ProfMat90. Caldas da Rainha: APM, vol. I, p. 155-171.

COLE, M.; JOHN-STEINER, V.; SCRIBNER, S.; SOUBERMAN, E. (Eds.). L. S. Vygotsky Mind in society: the development of higher psychological processes. Cambridge, Massachusetts: Harvard University Press, 1978.

FERNANDES, F. L. P.; FIORENTINI, D.; CRISTOVÃO, E. M. Investigações matemáticas e o desenvolvimento do pensamento algébrico de alunos de 6a série. Em: FIORENTINI, D.; CRISTOVÃO, E. M. (org.). Histórias e investigações de/em aulas de matemática. Campinas, SP: Editora Alínea, 2006, p. 227-244. 
FIORENTINI, D.; LORENZATO, S. Investigação em educação matemática: percursos teóricos e metodológicos. Campinas, SP: Autores Associados, 2006.

GÓMEZ CHACÓN, I. M. Matemática emocional: os afetos na aprendizagem matemática. Porto Alegre: Artmed, 2003.

JOHN-STEINER, V.; SOUBERMAN, E. Afterword. Em: COLE, M.; JOHN-STEINER, V.; SCRIBNER, S.; SOUBERMAN, E. (Eds.), L. S. Vygotsky Mind in society: the development of higher psychological processes. Cambridge, Massachusetts: Harvard University, 1978, p. 121-133.

LORENZATO, S. Para aprender matemática. Campinas, SP. Autores Associados, 2006.

NASSER, L.; TINOCO, L. A. de A. (coord.). Argumentação e provas no ensino da matemática. Rio de Janeiro: UFRJ/Projeto Fundão, 2003.

POLYA, G. A arte de resolver problemas. Tradução e adaptação de Heitor Lisboa de Araújo. 2a reimpressão. Rio de Janeiro: Interciência, 1995. (A obra foi publicada originalmente em inglês em 1945. A 1aㅡ ed. brasileira apareceu em 1975)

PONTE, J. P. da; BROCARDO, J.; OLIVEIRA, H. Investigações matemáticas na sala de aula. 1ạ ed., 1a reimp. Belo Horizonte: Autêntica, 2005.

PONTE, J. P. da; OLIVEIRA, H.; CUNHA, M. H.; SEGURADO, M. I. Histórias de investigações matemáticas. Lisboa: Instituto de Inovação Educacional, 1998.

OLIVEIRA, M. K. de. Aprendizado e desenvolvimento: um processo sócio-histórico. São Paulo: Scipione, 1993.

ROCHA, M. M. Um estudo do desenvolvimento de atividades investigativas na aprendizagem de matemática no ensino médio. 2009. 211f. Dissertação (Mestrado em Educação) - Programa de Pós-Graduação em Educação, Centro de Educação, Universidade Federal do Espírito Santo, Vitória.

SANTOS, V. M. P. dos. Avaliação de aprendizagem e raciocínio em matemática: métodos alternativos. Rio de Janeiro: Projeto Fundão, Instituto de Matemática, UFRJ, 1997.

SANTOS-WAGNER, V. M. P. dos. Resolução de problemas em matemática: uma abordagem no processo educativo. Boletim GEPEM, Rio de Janeiro, n. 53, p. 43-74, Jul./Dez. 2008.

SCHOENFELD, A. H. Heurísticas na sala de aula. Em: KRULIK, S.; REY, R. E. (org.). A resolução de problemas na matemática escolar. Tradução de Hygino H. Domingues, e Olga Corbo. São Paulo: Atual, 1997, p. 13 - 31. (A obra foi publicada originalmente em inglês em 1980.).

THOMPSON, A. G. A relação entre concepção de matemática e de ensino de matemática de professores na prática pedagógica. Tradução de Gilberto F. A. de Melo. Zetetiké, Campinas: CEMPEM - FE/Unicamp, v. 5, n. 8, p. 11 - 44, jul./dez. 1997. (Trabalho foi publicado originalmente em inglês em 1984). 